\title{
Persistence of a hypoglossal artery: case report
}

\author{
Persistência da artéria hipoglossa: relato de caso
}

Jorge Rufino Ribas Timi', Luiz Otavio de Mattos Coelho², Ricardo Scopel Pasini

\begin{abstract}
The authors present a case of persistent hypoglossal artery. Persistent hypoglossal artery is the second most common carotid-basilar anastomosis with a frequency of $0.02 \%$ to $0.09 \%$ and it can be associated with cerebrovascular disease. Diagnosis is by imaging methods and angiotomography is the method most often employed.
\end{abstract}

Keywords: carotid artery; hypoglossal artery; hypoglossal canal.

\section{Resumo}

Os autores apresentam o caso de persistência da artéria hipoglossa. A artéria hipoglossa é a segunda anastomose carótida-basilar mais comum, com frequência de 0,02\% a 0,09\%, podendo estar associada a doenças vasculares cerebrais. Seu diagnóstico se faz através de métodos de imagem, sendo a angiotomografia o método mais utilizado.

Palavras-chave: artéria carótida; artéria hipoglossa; canal hipoglosso. 


\section{INTRODUCTION}

Persistent hypoglossal artery is the second most common anomalous carotid-basilar anastomosis, while the most common is persistent trigeminal artery. ${ }^{1}$ The hypoglossal artery originates from the extracranial internal carotid as a large lateral branch, which rises vertically and passes through the hypoglossal canal, continuing as the basilar artery. ${ }^{2,3}$ Hypoplasia of the vertebral artery is frequently associated with a persistent hypoglossal artery, in which the hypoglossal artery maintains the blood flow of the vertebral artery. ${ }^{1}$

In the majority of cases this anomaly is asymptomatic, but it may compress the XII and IX cranial nerve pairs, causing paralysis in the first and neuralgia in the second. ${ }^{3}$

Definitive diagnosis of this anatomic variant is accomplished using imaging exams and computed angiotomography is currently the most commonly used method. ${ }^{4}$

\section{CASE REPORT}

A 59-year-old, male, asymptomatic patient was referred to the Vascular Surgery Service for investigation of $70 \%$ stenosis at the bifurcation of the left common carotid artery that had been found on color Doppler ultrasound.

Angiotomography of the carotids showed stenosis at the bifurcations of the left common carotid, estimated at $40 \%$, and a persistent hypoglossal artery (Figures 1, 2 and 3), with hypoplasia of the left vertebral artery. The hypoglossal artery continued to the basilar artery.

The patient was already on an antiplatelet drug, which was continued, and periodic follow-up appointments were made.

\section{DISCUSSION}

During the early phases of embryonic development cerebral circulation is provided by four pairs of arterial anastomoses connecting the dorsal aorta with the longitudinal neural arteries, which are located dorsally at the surface of the hindbrain. These anastomoses normally regress in the fetus or during the first years of life. Detection in adults is accidental and certain anastomoses may be associated with cerebrovascular diseases such as malformations, aneurysms, arteriovenous fistulas and atherosclerotic disease. ${ }^{1,5}$

In terms of frequency, persistent hypoglossal artery is slightly more common among women on the left side, is the second most frequent carotid-basilar anastomosis $(0.02 \%$ to $0.09 \%)$ and is bilateral in $1.4 \%$ of cases. ${ }^{1,6}$

The hypoglossal artery follows an ascending path with a slight posterior and medial curvature, arises from the posterior surface of the cervical internal carotid artery and is related to the $\mathrm{C} 1-\mathrm{C} 2$ space. It

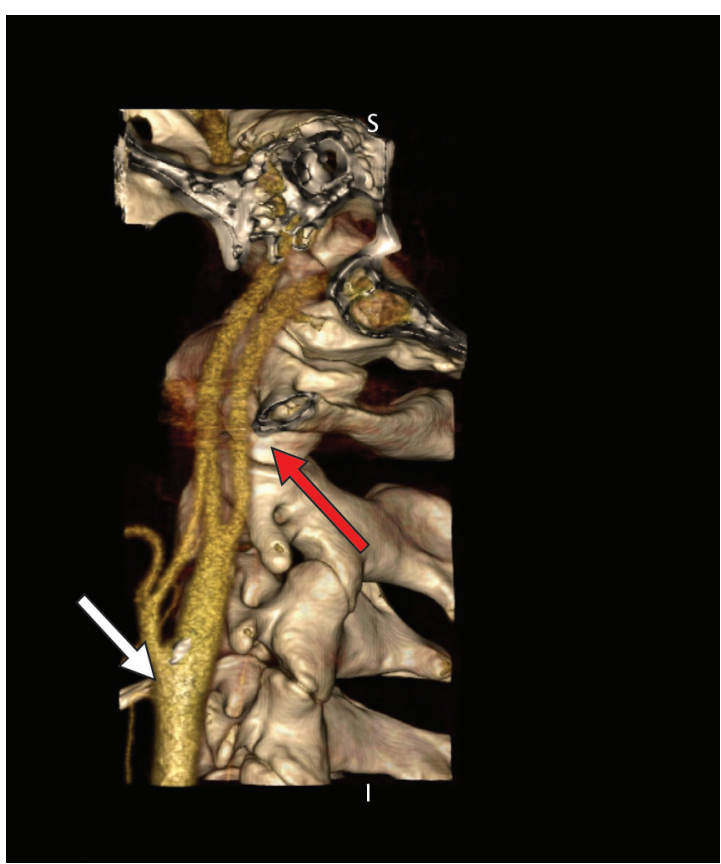

Figure 1. Bifurcation of the common carotid artery (white arrow) and persistent hypoglossal artery (red arrow).

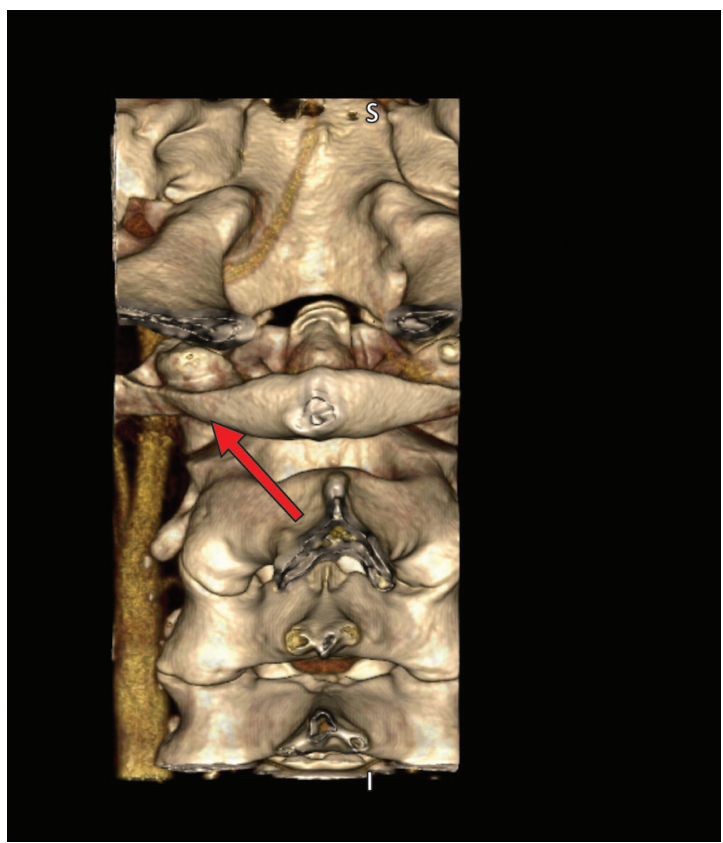

Figure 2. Hypoglossal artery passing through the hypoglossal canal (arrow). 


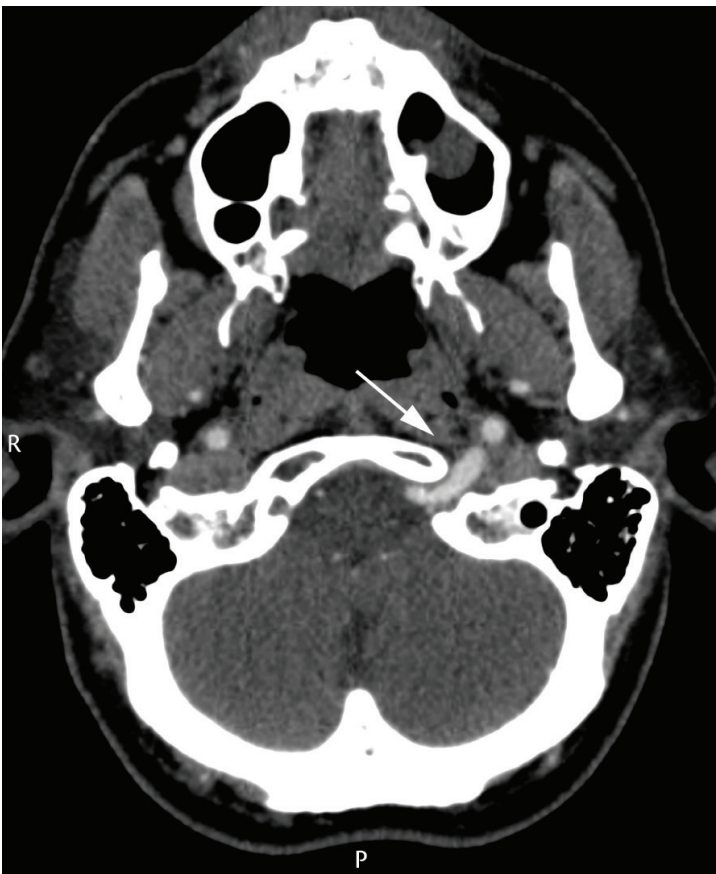

Figure 3. Tomography, transverse view, showing the hypoglossal artery passing through the hypoglossal canal (arrow).

penetrates the hypoglossal canal at the base of the skull, ending at the artery basilar. ${ }^{3,6}$ In the majority of cases it is associated with hypoplasia of the vertebral artery, and the posterior-inferior cerebellar artery may branch off from it, confirming the connection between the two during the embryonic period. ${ }^{7}$

Diagnosis is by imaging methods. Diagnosis by duplex scan is difficult because there are variations in normal extracranial vertebral artery anatomy. An absence of vertebral arteries on both sides may indicate occlusive vascular disease or arterial stenosis or may provide important clues for a diagnosis of persistence of fetal communications. ${ }^{8}$ Angiotomography has become the most common diagnostic method. ${ }^{3}$

During investigation, bone landmarks are the best criteria for identifying whether the hypoglossal artery penetrates the base of the skull via the canal of the hypoglossal nerve. ${ }^{1}$

The posterior part of the circle of Willis is inconstant because of hypoplasia of the vertebral arteries and the ipsilateral posterior communicating arteries when persistent hypoglossal artery is present.
Posterior cerebral circulation is therefore fed by the hypoglossal artery. ${ }^{2,3,6}$

In these cases, vascular compression may cause paralysis of the hypoglossal nerve (XII) and neuralgia of the glossopharyngeal nerve (IX). ${ }^{4}$

Surgical approaches to the cervical portion of the internal carotid artery are simplified by the fact that it does not have any branches in this segment. Notwithstanding, the Vascular Surgeon must be acquainted with the anatomic variations and anomalous branches that can occur in this arterial segment, in order to avoid traumatisms and complications during open procedures or endovascular surgery, including by planning transoperative cerebral protection methods.

\section{REFERENCES}

1. Pasco A, Papon X, Bracard S, Tanguy JY, Ter Minassian A, Mercier P. Persistent carotid-vertebrobasilar anastomoses: how and why differentiating them? J Neuroradiol. 2004;31(5):391-6. http:// dx.doi.org/10.1016/S0150-9861(04)97022-8

2. Kanematsu M, Satoh K, Nakajima N, Hamazaki F, Nagahiro S. Ruptured aneurysm arising from a basilar artery fenestration and associated with a persistent primitive hypoglossal artery: case report and review of the literature. J Neurosurg. 2004;101(3):532-5. PMid:15352614. http://dx.doi.org/10.3171/jns.2004.101.3.0532

3. Pasaoglu L, Hatipoglu HG, Vural M, Ziraman I, Ozcan HN, Koparal S. Persistent primitive hypoglossal artery and fenestration of posterior cerebral artery: CT and MR angiography. Neurocirugia. 2009;20(6):563-6. [citado 2013 maio 15]. http:// scielo.isciii.es/pdf/neuro/v20n6/7.pdf

4. Huynh-Le P, Matsushima T, Muratani H, Hikita T, Hirokawa E. Persistent primitive hypoglossal artery associated with proximal posterior inferior cerebellar artery aneurysm. Surg Neurol. 2004;62(6):546-51. PMid:15576127. http://dx.doi. org/10.1016/j.surneu.2004.03.018

5. Luh GY, Dean BL, Tomsick TA, Wallace RC. The persistent fetal carotid vertebrobasilar anastomoses. AJR Am J Roentgenol. 1999;172(5):1427-32. PMid:10227532. http://dx.doi. org/10.2214/ajr.172.5.10227532

6. Avcu S, Van der Schaaf I, Ozcan HN, Sengul I, Fransen H. Persistent hypoglossal artery detected incidentally in a hypertensive patient with intracerebral hemorrhage: a case report and review of the literature. Cases Journal. 2009:2:8175. http://www.casesjournal. com/content/2/1/8571

7. De Caro R, Parenti A, Munari PF. The persistent primitive hypoglossal artery: a rare anatomic variation with frequent clinical implications. Anat Anz. 1995;177(2):193-8. http://dx.doi. org/10.1016/S0940-9602(11)80073-7

8. Takahashi H, Tanaka H, Fujita N, Tomiyama N. Bilateral persistent hypoglossal arteries: MRI findings. Br J Radiol. 2012;85(1010):e0468. PMid:22308227 PMCid:PMC3473955. http://dx.doi. org/10.1259/bjr/21939976 
Correspondence Jorge Rufino Ribas Timi Rua Professora Rosa Saporski, 469 CEP 80810-120 - Curitiba (PR), Brazil Tel.: +55 (41) 3244-5000 E-mail: jorgetimi@terra.com.br

Author information

JRRT é Professor Associado de Cirurgia Vascular da Universidade Federal do Paraná (UFPR), Coordenador do Instituto da Circulação de Curitiba e Titular da SBACV.

LOMC é Médico Radiologista da Clínica DAPE. RSP é Residente de Cirurgia Vascular do Hospital Angelina Caron.

Author contributions Conception and design: JRRT, RSP Analysis and interpretation: JRRT, RSP Data collection: IRRT, LOMC, RSP Writing the article: JRRT, RSP

Critical revision of the article: JRRT Final approval of the article*: JRRT, LOMC, RSP

Statistical analysis: N/A Overall responsibility: JRRT

*All authors have read and approved of the final version of the article submitted to I Vasc Bras. 